\title{
Segregation of spermatozoa within sperm storage tubules of fowl and turkey hens
}

\author{
L. M. King ${ }^{1}$, J. P. Brillard ${ }^{2}$, W. M. Garrett ${ }^{1}$, M. R. Bakst ${ }^{1 *}$ \\ and A. M. Donoghue ${ }^{1}$ \\ ${ }^{1}$ Germplasm and Gamete Physiology Laboratory, Agricultural Research Service, US \\ Department of Agriculture, Beltsville, MD 20705, USA; and 'INRA Station de Recherches \\ Avicoles, Centre de Recherches de Tours-Nouzilly, France
}

In avian species, spermatozoa reside in the oviduct for prolonged periods in specialized structures known as sperm storage tubules, but little is known about the relative distribution of spermatozoa in these tubules after successive inseminations by different males. The staining efficacies of various fluorescent dyes for fowl and turkey spermatozoa were evaluated to investigate one proposed mechanism of sperm competition. Hens were then inseminated at different intervals with stained and unstained spermatozoa to observe the spatial distribution of spermatozoa within the storage tubules. Several novel fluorescent lipophilic tracers that successfully stain mammalian spermatozoa either did not stain fowl or turkey spermatozoa, or greatly impaired sperm motility. In contrast, Hoechst 33342 readily stained sperm nuclei (fowl: $25 \mathrm{nmol} \mathrm{I}^{-1}$; turkey: $77 \mathrm{nmol} \mathrm{I}^{-1}$ ) within $4 \mathrm{~h}$ without inhibiting sperm motility, or affecting fertility or the hatching ability of the eggs. Hens were tandemly inseminated with equal numbers of stained or unstained spermatozoa at $24 \mathrm{~h}$ intervals and were killed $24 \mathrm{~h}$ after the final insemination to study sperm entry and storage within the tubules. Oviductal mucosa containing sperm storage tubules was removed, and individual tubules were classified as containing stained spermatozoa, unstained spermatozoa, a mixture of stained and unstained spermatozoa, or as not containing spermatozoa. Results from the present study indicate that spermatozoa from two different inseminations generally segregate into different storage tubules in both fowl and turkey hens. Storage tubules containing mixed populations of spermatozoa were found in only $4 \%$ of fowl and $12 \%$ of turkey storage tubules examined. Thus, the mechanism of last-male precedence does not appear to be due to the stratification of spermatozoa within the tubules.

\section{Introduction}

A significant feature of avian reproductive physiology is the ability of hens to store spermatozoa for prolonged periods. This is due to the presence of sperm storage tubules (SST), which are epithelial invaginations located mainly in the uterovaginal junction of the oviduct, but also present in smaller quantities in the infundibulum (Van Krey et al., 1966). Spermatozoa transferred to the vagina by copulation or artificial insemination (Al) move through the vagina and ascend to the SST in the uterovaginal junction mucosa. Here spermatozoa enter the SST for variable periods, depending on the species, reproductive status and age of the female. Stored spermatozoa are released from the SST over time when the female is producing eggs to ensure that spermatozoa are present at the site of fertilization (Bakst et al., 1994). The mechanisms surrounding sperm selection before their entry into the SST, as well as their release from the SST, are not well characterized, but it is known that only motile and morphologically normal spermatozoa enter the

*Correspondence

Email: murray@anri.barc.usda.gov
SST (Allen and Grigg, 1958). Maximum storage capacity of spermatozoa in the SST is reached within 2 days of $\mathrm{Al}$ in turkeys (Brillard and Bakst, 1990; Brillard, 1993) and within 1 day in fowl hens (Brillard, 1993). Quantification of the number of spermatozoa stored within the SST originally relied on histological procedures, but more recently has relied on moderate grinding (Brillard and Bakst, 1990), collagenase digestion (Brillard, 1993) or homogenization of the SST (McLean and Froman, 1996).

Radiolabels and fluorescent stains have been used to improve visualization of spermatozoa within the SST. Hoechst 33342 (bisbenzamide) is a fluorescent dye that binds to the DNA of live cells, and is nontoxic and nonmutagenic at low concentrations before exposure to UV radiation (Latt and Stetten, 1976; Durand and Olive, 1982). Bakst (1994) first reported the use of Hoechst 33342 to label turkey spermatozoa for improved visualization of spermatozoa stored within the SST and infundibulum. These qualitative studies described the differential rates at which spermatozoa filled SST in turkey hens before and after egg laying. Bakst (1994) found a slight decrease in egg fertility and in the hatching ability of eggs after a dose of $90 \mathrm{nmol}$ Hoechst $33342 \mathrm{I}^{-1}$. McDaniel et al. (1997) used Hoechst- 
labelled spermatozoa to quantify the storage capacity of the SST after homogenization of uterovaginal junction tissue. They used $116 \mathrm{nmol}$ Hoechst $33342 \mathrm{I}^{-1}$ to label fowl spermatozoa and no observations were reported of the SST containing spermatozoa before homogenization.

The application of fluorescent dyes for staining spermatozoa has also been used to study competitive fertilization. Paternity patterns in many species have demonstrated a lastmale mating advantage, in which spermatozoa from the last male fertilizes most eggs during the first few days after the last insemination. This phenomenon has been termed 'lastmale sperm precedence' (Birkhead and Møller, 1992). Several authors suggested that last-male sperm precedence in fowl was a result of sperm stratification within the SST (Burke and Ogasawara, 1969; Compton et al., 1978; Christensen, 1981). Van Krey et al. (1981) used radiolabelled spermatozoa to study the mechanism of last-male sperm precedence in fowl hens. They performed inseminations at $5 \mathrm{~h}$ intervals using $\left[{ }^{3} \mathrm{H}\right]$ thymidine-labelled and -unlabelled spermatozoa, and found both labelled and unlabelled spermatozoa within the SST. Last-male precedence has not been observed when inseminations occurred at intervals of less than $4 \mathrm{~h}$.

Competitive fertilization has also been studied in many mammals, including rabbits (Overstreet and Adams, 1971; Parrish and Foote, 1985), bulls (Davis et al., 1987) and humans (Blazak et al., 1981). The fluorochromes used in these studies, fluorescein isothiocyanate and tetramethylrhodamine, label the proteins on spermatozoa, but also tend to reduce sperm motility (Mellish and Baker, 1970; Davis et al., 1987). Alternatively, newer lipophilic fluorescent dyes permeate the plasmalemma of mammalian spermatozoa without affecting sperm motility (Youakim et al., 1994; Miller et al., 1998). It is not known how these lipophilic fluorochromes affect the motility of spermatozoa, fertilizing capacity and embryo mortality in poultry.

The aim of the present study was to evaluate one of the proposed mechanisms of sperm competition, the concept of last-male precedence, in fowl and turkey hens. Through the use of tandem inseminations with stained and unstained spermatozoa, respectively, the study was intended to provide an insight into the possible stratification of spermatozoa in the SST in relation to last-male precedence. It has been suggested that the last spermatozoa to be transferred into the oviduct overlay spermatozoa already residing in the SST and, therefore, are the first to be released and subsequently transported to the site of fertilization (Compton et al., 1978). However, the biological basis of last-male precedence with respect to sperm stratification in the SST has been questioned (Birkhead et al., 1995).

\section{Materials and Methods}

\section{Animals}

ISA Brown (Hubbard-ISA, Lyon) fowl hens and males (Gallus domesticus), aged 30-40 weeks, and Large White BUTA (British United Turkeys of America, Lewisburg, WV) breeder turkeys (Meleagris gallopavo), aged 30-45 weeks, were used in this study. Experiments involving fowl and turkeys were conducted at INRA (Nouzilly) and at ARS (USDA, Beltsville, MD), respectively. Birds were maintained in environmentally controlled houses on a $14 \mathrm{~h}$ light:10 h dark photoperiod and were housed individually either in cages (fowls and turkey hens) or in groups of 8-10 in pens (male turkeys). Feed and water were provided ad libitum. Semen was collected by abdominal massage (Burrows and Quinn, 1937) and spermatozoa were stained before inseminations as described below. Hens were killed $24 \mathrm{~h}$ after the second $\mathrm{Al}$ was performed by injection of $2 \mathrm{ml}$ $6 \%(\mathrm{w} / \mathrm{v})$ sodium pentobarbital into the wing vein and exsanguination (fowl hens), or were killed by cervical dislocation (turkey hens).

\section{Staining of spermatozoa and sperm motility estimates}

Semen samples from eight to ten male fowl were pooled. Spermatozoa were labelled by diluting $1 \mathrm{ml}$ semen with $2 \mathrm{ml}$ Lake's diluent (Lake and Ravie, 1982) and adding $50 \mu \mathrm{l}$ of $1 \mathrm{mg}$ Hoechst $33342 \mathrm{ml}^{-1}$ (Molecular Probes, Eugene, OR). The diluted fowl semen was placed on an orbital shaker at 120 r.p.m. for $4 \mathrm{~h}$ at $4^{\circ} \mathrm{C}$ before use. Semen from seven male turkeys was pooled and spermatozoa were labelled by diluting $1 \mathrm{ml}$ semen with $3 \mathrm{ml}$ Beltsville poultry semen extender (BPSE; Continental Plastics, Delvan, WI) and adding $20 \mu \mathrm{l}$ of $10 \mathrm{mg}$ Hoechst $33342 \mathrm{ml}^{-1}$. The diluted turkey semen was placed on an orbital shaker at 120 r.p.m. for $4 \mathrm{~h}$ at $22^{\circ} \mathrm{C}$ to stain the sperm nuclei.

For the different lipophilic dyes, DiQ, DiOC 16 , Dil, DilSP and CellTracker ${ }^{\text {TM }}$ Orange (all obtained from Molecular Probes, Eugene, OR), staining of spermatozoa was performed according to manufacturer's recommendations at

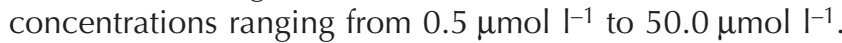
After each incubation, $100 \%$ of spermatozoa were stained with Hoechst 33342. For the remaining stains, a minimum of 100 spermatozoa in duplicate was evaluated at $\times 40$ using dual fluorescence and phase contrast microscopy.

Sperm motility estimates were performed in duplicate by the same person for both the fowl and turkey spermatozoa, using the swirling method. Approximately $20 \mu$ of diluted stained and unstained semen was placed on a slide and viewed at $\times 40$ using dual fluorescence and phase contrast microscopy.

\section{Fertility}

A total of $30 \mathrm{fowl}$ hens or 30 turkey hens were inseminated once with $200 \times 10^{6}$ stained ( $n=15$ hens) or unstained ( $n=15$ hens) spermatozoa to establish that staining with Hoechst 33342 did not affect the fertilizing ability of spermatozoa. Eggs were incubated and candled after 7 days (fowl) or 10 days (turkey) of incubation. Eggs considered as infertile were opened and evaluated by stereomicroscopy to assess possible early embryo mortality. Duration of fertility was determined as the number of days from the day after insemination to oviposition of the last fertilized egg (Romanoff and Romanoff, 1963). 
Table 1. Efficacy of different fluorescent stains for labelling spermatozoa from several species

\begin{tabular}{|c|c|c|c|c|c|}
\hline Stain & Concentration & $\begin{array}{c}\text { Percentage of } \\
\text { stained cells }(\%)^{\mathrm{a}}\end{array}$ & $\begin{array}{l}\text { Percentage of } \\
\text { sperm motility }\end{array}$ & Species & Reference \\
\hline \multirow[t]{3}{*}{ DiQ } & $2.5 \mu \mathrm{mol} \mathrm{I-1}$ & $\mathrm{nr}$ & $\mathrm{nr}$ & Mouse & Youakim et al., 1994 \\
\hline & $75.0 \mu \mathrm{mol} \mathrm{I}^{-1}$ & 66 & 43 & Bull & Miller et al., 1998 \\
\hline & $20.0-50.0 \mu \mathrm{mol} \mathrm{I}^{-1}$ & $10-40$ & 30 & Fowl & Present study \\
\hline \multirow{2}{*}{$\mathrm{DiOC}_{16}$} & $75.0 \mu \mathrm{mol} \mathrm{I-1}$ & 73 & 46 & Bull & Miller et al., 1998 \\
\hline & $20.0-50.0 \mu \mathrm{mol} \mathrm{I}^{-1}$ & $10-30$ & 20 & Fowl & Present study \\
\hline Dil & $9.0 \mu \mathrm{mol} \mathrm{I}^{-1}$ & $<10$ & $<10$ & Fowl & Present study \\
\hline Dil-SP & $11.5 \mu \mathrm{mol} \mathrm{I}{ }^{-1}$ & $<10$ & $<10$ & Fowl & Present study \\
\hline \multicolumn{6}{|c|}{ CellTracker ${ }^{\mathrm{TM}}$} \\
\hline Orange & $0.5 \mu \mathrm{mol} \mathrm{I}^{-1}$ & $<10$ & $<10$ & Fowl & Present study \\
\hline Hoechst & $7.6 \mathrm{nmol} \mathrm{I}^{-1}$ & $\mathrm{nr}$ & 100 & Horse & Thomas and Ball, 1996 \\
\hline \multirow{5}{*}{33342} & $7.6 \mathrm{nmol} \mathrm{I}^{-1}$ & 100 & 100 & Bull & Johnson et al., 1987 \\
\hline & $116.0 \mathrm{nmol} \mathrm{I}^{-1}$ & $\mathrm{nr}$ & $\mathrm{nr}$ & Fowl & McDaniel et al., 1997 \\
\hline & $25.0 \mathrm{nmol} \mathrm{I}^{-1}$ & 100 & 100 & Fowl & Present study \\
\hline & $90.0 \mathrm{nmol} \mathrm{I}^{-1}$ & 100 & 100 & Turkey & Bakst, 1994 \\
\hline & $77.0 \mathrm{nmol} \mathrm{I}^{-1}$ & 100 & 100 & Turkey & Present study \\
\hline
\end{tabular}

aStaining was performed according to manufacturer's recommendations or as indicated in the reference.

bSperm motility was estimated by the swirling technique or as indicated in the reference.

nr: not reported.

\section{Al procedures}

Tandem inseminations were performed at $24 \mathrm{~h}$ intervals in fowl hens using $200 \times 10^{6}$ spermatozoa for each insemination. In half of the experimental hens, the first Al was performed using stained spermatozoa and the second $\mathrm{Al}$ was performed using unstained spermatozoa. The other half of the experimental hens was inseminated in the reverse order (first with unstained spermatozoa and then with stained spermatozoa). The same procedure was followed for turkey hens, except that $275 \times 10^{6}$ stained or unstained spermatozoa were used in the Als.

\section{Tissue preparation and microscopy}

Uterovaginal junction mucosa containing SST was removed and folds containing the SST were separated from the underlying muscularis mucosa. Small pieces (approximately $2 \mathrm{~mm}^{2}$ ) of mucosa containing SST were spread on a glass slide, moistened with $0.9 \%(\mathrm{w} / \mathrm{v})$ saline and covered with a glass coverslip. Fluorescent microscopy (Axioplan 2 Zeiss microscope) was performed at $\times 40$ using a DIC filter. Individual SSTs ( $n=50-100$ per hen) were classified as containing stained spermatozoa, unstained spermatozoa, mixed (both stained and unstained) spermatozoa or not containing spermatozoa. Dual transmitted light and fluorescent images were acquired with a kappa image capture system (Fisher Bioblock Scientific, Illkirch) or with a Zeiss LSM 410 laser scanning confocal microscope (Carl Zeiss Inc., Thornwood, NY) using a C-apo $\times 40$ water immersion objective (1.2 NA) at a zoom factor of two. Bright field transmitted light images were obtained by illumination of the samples with the $633 \mathrm{~nm}$ line of a helium-neon laser and captured with the transmitted light detector. Hoechst 33342-labelled nuclear chromatin was excited with the $351 \mathrm{~nm}$ line of an argon ion laser, and the emitted light was passed through a $397 \mathrm{~nm}$ long-pass filter. The individual optical sections were pseudo-coloured and digitally recombined into a single composite image using LSM software (Carl Zeiss Inc.).

\section{Statistical analysis}

Data were reported as mean \pm standard error. The fertility data were analysed by a paired $t$ test using the Prism program (GraphPad Software, Inc., San Diego, CA). The sperm stratification data were analysed by the maximum likelihood method for the analysis of generalized logits in Proc Catmod (SAS/STAT ${ }^{\circledR}$, Version 8; SAS Institute, Inc., Cary, NC). A P value of $<0.05$ was considered significant.

\section{Results}

Several fluorescent lipophilic tracers that successfully stain mammalian sperm membranes (DiQ, DiOC ${ }_{16}$, Dil, Dil-SP) either did not stain fowl or turkey spermatozoa, or stained the spermatozoa, but greatly impaired sperm motility (Table 1). Staining was unsuccessful when DMSO (dimethylsulphoxide), DMF (dimethylformamide) or 100\% ethanol was used as a solvent or when a probe that is cleaved into a 
Table 2. Effect of insemination with Hoechst 33342-labelled spermatozoa on egg production, fertility and the hatching ability of eggs in fowl and turkey hens

\begin{tabular}{|c|c|c|c|c|}
\hline & \multicolumn{2}{|c|}{ Fowl hen } & \multicolumn{2}{|c|}{ Turkey hen } \\
\hline & $\begin{array}{c}\text { Unstained } \\
\text { spermatozoa }\end{array}$ & $\begin{array}{c}\text { Stained } \\
\text { spermatozoa }\end{array}$ & $\begin{array}{c}\text { Unstained } \\
\text { spermatozoa }\end{array}$ & $\begin{array}{c}\text { Stained } \\
\text { spermatozoa }\end{array}$ \\
\hline Number of hens & 30 & 30 & 30 & 30 \\
\hline Number of eggs laid & 255 & 259 & 236 & 240 \\
\hline Embryo mortality $<7$ days & 5 & 4 & 5 & 1 \\
\hline Embryo mortality $7-18$ days & 1 & 1 & 1 & 0 \\
\hline Embryo mortality $>18$ days & 7 & 4 & 0 & 1 \\
\hline Number of eggs hatched & 112 & 130 & 40 & 37 \\
\hline Maximum duration of fertility (days) & 18 & 20 & 31 & 31 \\
\hline
\end{tabular}

Concentration of Hoechst 33342: fowl: $25 \mathrm{nmol} \mathrm{I}^{-1}$; turkey: $77 \mathrm{nmol} \mathrm{I}^{-1}$.

(a)

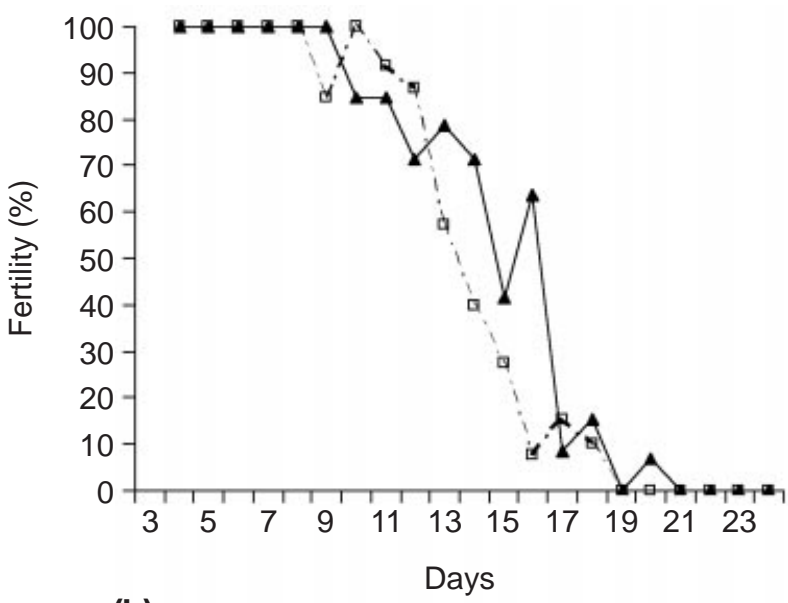

(b)

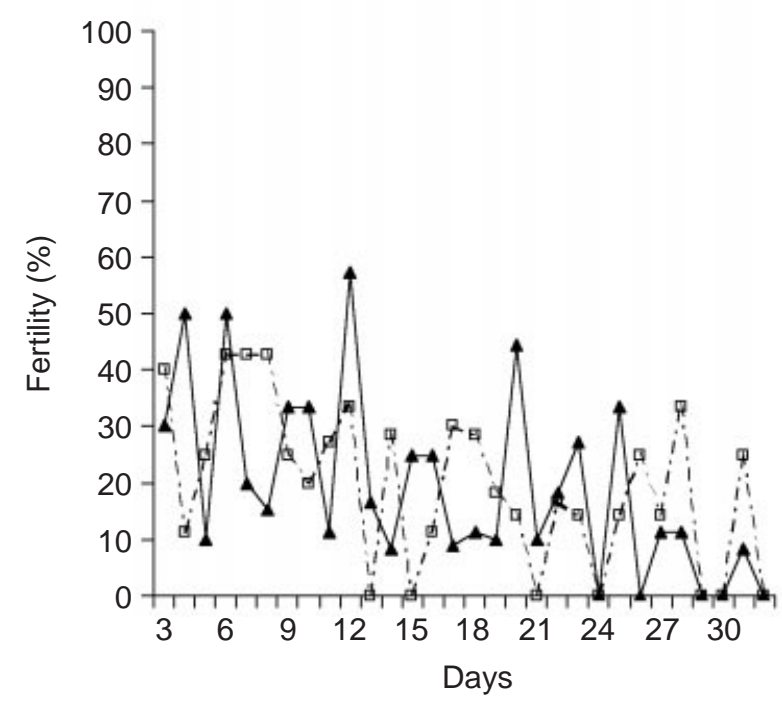

Fig. 1. Fertility of (a) fowl hens (Gallus domesticus) and (b) turkey hens (Meleagris gallopavo) after one insemination with $200 \times 10^{6}$ unstained $(\square$, control) spermatozoa or Hoechst 33342-stained $(\mathbf{A})$ spermatozoa $\left(25 \mathrm{nmol} \mathrm{I}^{-1}\right), n=30$ per group. fluorescent product inside cells (CellTracker ${ }^{\mathrm{TM}}$ Orange) was used. Of the several dyes tested, only Hoechst 33342 stained fowl and turkey sperm nuclei without affecting sperm motility. There were no significant differences within fowl and turkey hens inseminated with stained or unstained semen in the percentage of fertility, number of eggs laid, embryo mortality or the number of eggs hatched (Fig. 1; Table 2).

Spermatozoa from tandem inseminations generally segregated into different SST, regardless of species. In SST that contained mixed (both stained and unstained) spermatozoa, the spermatozoa were distributed randomly, and not layered or stratified into discrete populations (Fig. 2). SST containing mixed populations of spermatozoa (both stained and unstained) were found in approximately $4 \%$ of the fowl SST and in approximately $12 \%$ of the turkey SST examined, and the order of insemination had no significant effect on this parameter (Table 3).

The order of insemination did not significantly affect the percentages of stained or unstained spermatozoa occupying the SST $24 \mathrm{~h}$ after insemination in either the fowl or turkey hens (Table 3). Most of the fowl SST observed contained stained spermatozoa, regardless of the order of insemination. In turkey hens, most of the SST observed either contained stained spermatozoa or did not contain spermatozoa, depending on the order of insemination; however, this difference was not significant. When comparisons were made between the two species, fowl hens were significantly more likely to have SST that contained spermatozoa (either stained or unstained) than turkeys, regardless of the order of insemination. However, turkeys were more likely to have SST that contained mixed (both stained and unstained) spermatozoa than were fowls, regardless of the order of insemination.

\section{Discussion}

This study indicates that many of the available fluorescent lipophilic dyes that have been used to label somatic cells (Honig and Hume, 1989; Ledley et al., 1992; Baker et al., 

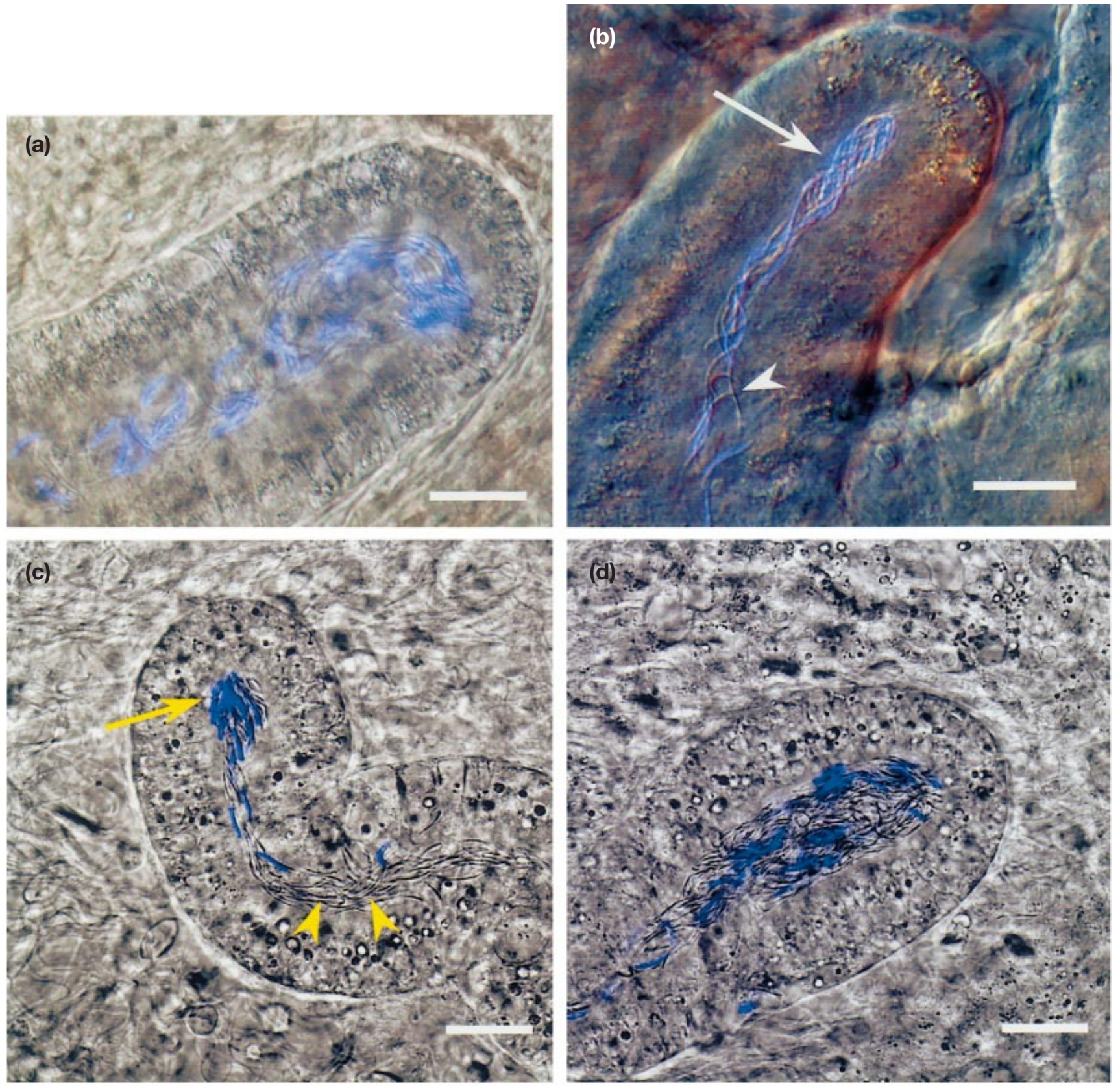

Fig. 2. Photomicrographs of sperm storage tubules containing mixed (both Hoechst 33342-stained and unstained) populations of spermatozoa from (a,b) fowl hens (Gallus domesticus) and (c,d) turkey hens (Meleagris gallopavo). Arrows indicate Hoechst 33342stained spermatozoa, arrowheads designate unstained spermatozoa. Scale bars represent $25 \mu \mathrm{m}$.

1997; Vercelli et al., 2000) were either ineffective in staining or damaging to fowl and turkey spermatozoa. In addition, many lipophilic dyes used to label mammalian spermatozoa (Youakim et al., 1994; Miller et al., 1998) were inadequate for fowl and turkey spermatozoa. For the purposes of the present study, successful labelling was considered as the incorporation of the fluorescent lipid analogues present in the dyes into or through the sperm membranes without affecting sperm motility. The actual mechanisms involved in the labelling process are not known, although it has been established that poultry spermatozoa differ from mammalian spermatozoa both in glycolipid content and in phospholipid saturation (Parks and Lynch, 1992). Thus, the unique biophysical composition of cell membranes in these species may affect the penetration and binding of lipophilic fluorescent dyes and, therefore, may explain the differential staining capacity between mammalian and poultry spermatozoa.

Despite the lack of two validated staining procedures to label spermatozoa adequately in a differential manner, 
Table 3. Distribution of stained and unstained spermatozoa in sperm storage tubules (SST) of fowl and turkey hens after tandem inseminations

\begin{tabular}{lccccc}
\hline & \multicolumn{2}{c}{$\begin{array}{c}\text { Fowl hens } \\
(n=7)\end{array}$} & & \multicolumn{2}{c}{$\begin{array}{c}\text { Turkey hens } \\
(n=6)\end{array}$} \\
\cline { 2 - 3 } & $\begin{array}{c}\text { Stained- } \\
\text { unstained }\end{array}$ & $\begin{array}{c}\text { Unstained- } \\
\text { stained }\end{array}$ & & $\begin{array}{c}\text { Stained- } \\
\text { unstained }\end{array}$ & $\begin{array}{c}\text { Unstained- } \\
\text { stained }\end{array}$ \\
\hline Percentage of SST containing: & & & & & \\
$\quad$ Stained spermatozoa & $59.8 \pm 6.0$ & $48.0 \pm 11.3$ & & $27.6 \pm 7.5$ & $42.9 \pm 11.0$ \\
$\quad \begin{array}{l}\text { Unstained spermatozoa } \\
\text { No spermatozoa }\end{array}$ & $13.7 \pm 3.7$ & $19.3 \pm 4.0$ & & $19.8 \pm 6.4$ & $11.7 \pm 2.5$ \\
Mixed spermatozoa & $21.4 \pm 2.8$ & $30.3 \pm 10.4$ & & $36.5 \pm 7.8$ & $35.6 \pm 9.8$ \\
& $5.1 \pm 2.8$ & $2.5 \pm 1.2$ & & $16.1 \pm 5.4$ & $9.8 \pm 8.6$ \\
\hline
\end{tabular}

tandem inseminations with stained (Hoechst 33342) and unstained spermatozoa proved sufficient to determine the effects of staining on hen fertility and also to study competitive fertilization and last-male precedence. Bakst (1994) and McDaniel et al. (1997) reported that use of Hoechst 33342-stained spermatozoa resulted in a decrease in the hatching ability of eggs. However, both of these studies used a higher concentration of Hoechst 33342 (90 nmol I-1 and $116 \mathrm{nmol} \mathrm{I}^{-1}$, respectively) compared with the present study in which $25 \mathrm{nmol} \mathrm{I}^{-1}$ in fowl and $77 \mathrm{nmol} \mathrm{I}$ in turkeys were used. Higher concentrations of Hoechst 33342 probably contributed to the increased incidence of embryo mortality and to the transfer of fluorescent dye from stained resident spermatozoa to unstained resident spermatozoa and surrounding SST epithelium (Bakst, 1994). In the present study, considerable effort was made to find the minimum concentration of Hoechst 33342 that would successfully label all spermatozoa, but that would not leach into the lumen of SST or affect sperm motility and subsequent egg fertility. No evidence of transfer of Hoechst 33342 between stained and unstained spermatozoa residing in the SST was observed. In addition, no staining of SST epithelial cell nuclei was observed up to 4 days after insemination (data not shown). When higher concentrations of Hoechst 33342 were used to stain spermatozoa used for insemination, SST epithelial cell nuclei were often fluorescent (Bakst, 1998). However, in the present study, fluorescent SST epithelial nuclei were not observed, which strongly supports the assertion that there was no leakage of the Hoechst 33342-labelled spermatozoa within the SST.

There were no significant differences between the control (unstained) spermatozoa and the Hoechst 33342stained spermatozoa in fowl or turkey hen fertility, number of eggs laid, embryo mortality or number of hatched eggs. In addition, pilot studies were conducted in which the number of spermatozoa trapped in the outer perivitelline layer was determined. This value is positively correlated with the number of spermatozoa residing in the SST (Brillard and Bakst, 1990), with numbers of spermatozoa inseminated (Wishart, 1987) and with flock fertility (Staines et al., 1998). There was no significant difference in the number of perivitelline spermatozoa between hens that had been inseminated with unstained spermatozoa only and hens inseminated with stained spermatozoa only (data not shown). This finding indicates that Hoechst 33342 at the concentrations used in the present study did not affect the ability of spermatozoa to reach and enter the SST, or to reach the site of fertilization.

Compared with fowl, higher percentages of turkey SST did not contain spermatozoa after tandem inseminations. Although highly variable, this finding may be a consequence of the larger population of SST within the turkey (approximately 24000 SST; Goodrich-Smith and Marquez, 1978) compared with that in fowl (approximately 3000 SST; Brillard et al., 1998). Hens inseminated before the onset of egg production have significantly more SST that contained spermatozoa, and more SST that are filled to maximum capacity than do hens inseminated after the onset of egg production (Mclntyre et al., 1982; Brillard and Bakst, 1990; Bakst, 1994). There may be some type of activation of the SST, which occurs just before egg production, at which time most of the SSTs are able to store spermatozoa. After the onset of egg production, hormonal changes (Brillard et al., 1987) or distention of the oviduct associated with egg laying (Bakst, 1994) may interfere with sperm storage in the SST. Events associated with oviposition and ovulation have been shown to influence the rate of sperm release from the SST in fowl hens (Bushman et al., 1985). In addition, certain folds of the uterovaginal junction examined in the present study in both fowl and turkey contained SST that did not contain spermatozoa, or contained either all stained or all unstained spermatozoa. This pattern was observed repeatedly in different regions of the same uterovaginal junction and, therefore, it is unlikely that $\mathrm{Al}$ was the cause. Alternatively, this finding may imply the presence of channels in the oviduct through which the spermatozoa travel to the SST and avoid becoming trapped in mucus sheets (for a review of oviductal sperm transport mechanisms, see Bakst et al., 1994).

The present study is the first to distinguish spermatozoa from two different inseminations within the same SST. Although Van Krey et al. (1981) described stratification of labelled and unlabelled spermatozoa in the SST, the light micrographs provided were poor. The question of sperm competition, that is, which spermatozoon does actually fertilize the ovum, has been hampered by the inability to visualize directly what is occurring within the SST with 
regards to sperm uptake, storage and displacement. The idea of stratification of ejaculates was suggested by Compton et al. (1978) as an explanation of last-male sperm precedence ('first in-last out'). Subsequently, Lessells and Birkhead (1990) composed three different mathematical models of sperm competition in an attempt to describe sperm precedence: sperm stratification, passive sperm loss and sperm displacement. These models were tested further by Birkhead and Biggins (1997) and it was determined that passive sperm loss was the most likely explanation for sperm precedence. Likewise, results from the present study and those of Birkhead et al. (1995), do not support the stratification model of last-male sperm precedence. However, observations in the present study show that spermatozoa segregate into different SST, or occasionally mix within the same SST. Furthermore, the order of insemination did not significantly affect the percentages of different populations of spermatozoa (in the present study, stained or unstained) within the SST. However, the number of spermatozoa within the SST was not quantified and, therefore, evaluations regarding passive sperm loss or sperm displacement could not be made in this study.

More tubules contained stained rather than unstained spermatozoa, in both the fowl and the turkey. This was an unexpected result that is difficult to interpret. It is possible that visualization of unstained spermatozoa was hindered by the fluorescence of the stained spermatozoa; however, this seems unlikely. It is also possible that the staining process affects sperm entry or exit from the SST. The specific mechanisms of filling and emptying of the SST are unknown, but are affected by sperm motility, the age of the hen and the onset of egg production. In the present study there were no obvious differences in sperm quality, as the stained and unstained spermatozoa both came from the same pool of semen, and the same group of males was used for each insemination. In addition, no differences were observed in fertilization parameters or in the hatching ability of eggs. The significance of the finding that more tubules contained stained than unstained spermatozoa is worthy of further study.

The present study has shown that lipophilic dyes that stain mammalian spermatozoa without inhibiting sperm motility do not perform in the same manner with poultry spermatozoa, emphasizing the role of species differences in sperm membrane composition. As first shown by Bakst (1994), Hoechst 33342 can be used successfully to label turkey spermatozoa to improve understanding of the dynamics of oviductal sperm transport and storage. In the present study, this procedure was modified for use with both fowl and turkey spermatozoa, and concentrations of stain were used that did not affect fertility or transfer of the label to adjacent unstained spermatozoa or tissue.

In conclusion, results from sperm competition studies reported here indicate that spermatozoa generally segregated into different SST in both fowl and turkey hens after tandem inseminations; sperm stratification within the SSTs was not observed. SST containing mixed populations of both stained and unstained spermatozoa were found in $4 \%$ of fowl SST and in $12 \%$ of turkey SST examined. Thus, the mechanism of last-male precedence does not appear to be due to the stratification of spermatozoa within the SST of fowl or turkey hens.

The authors are grateful for the technical assistance of M-F. Scheller; for the animal care and handling provided by J. D. Terlot, W. Smoot and D. Bushling; and for the statistical services provided by B. Vinyard, Biometrical Consulting Service, USDA. This research was supported in part by an NRI Competitive Grant No. 98-35203-6221 awarded to L. M. King and by fellowships from the Organisation for Economic Cooperation and Development, awarded to L. M. King and M. R. Bakst.

\section{References}

Allen TE and Grigg GW (1958) Sperm transport in the fowl Australian Journal of Agricultural Research 8 788-799

Baker GR, Sullam PM and Levin J (1997) A simple, fluorescent method to internally label platelets suitable for physiological measurements American Journal of Hematology 56 17-25

Bakst MR (1994) Fate of fluorescent stained sperm following insemination: new light on oviducal sperm transport and storage in the turkey Biology of Reproduction $\mathbf{5 0}$ 987-992

Bakst MR (1998) Structure of the avian oviduct with emphasis on sperm storage in poultry Journal of Experimental Zoology 282 618-626

Bakst MR, Wishart G and Brillard JP (1994) Oviducal sperm selection, transport and storage in poultry Poultry Science Reviews 5 117-143

Birkhead TR and Biggins JD (1997) Sperm competition mechanisms in birds: models and data Behavioural Ecology 9 253-260

Birkhead TR and Møller AP (1992) Sperm precedence and mechanisms of sperm competition. In Sperm Competition in Birds, Evolutionary Causes and Consequences pp 69-83. Academic Press Inc., San Diego, CA

Birkhead TR and Møller AP (1993) Sexual selection and the temporal separation of reproductive events: sperm storage data from reptiles, birds and mammals Biological Journal of the Linnean Society $\mathbf{5 0}$ 295-311

Birkhead TR, Wishart G and Biggins JD (1995) Sperm precedence in the domestic fowl Proceedings Royal Society of London Series B 266 1759-1764

Blazak WF, Overstreet JW, Katz DR and Hanson FW (1981) A competitive in vitro assay of human sperm fertilizing ability utilizing contrasting fluorescent sperm markers Journal of Andrology 3 165-171

Brillard JP (1993) Sperm storage and transport following natural mating and artificial insemination Poultry Science 71 923-928

Brillard JP and Bakst MR (1990) Quantification of spermatozoa in the sperm-storage tubules of turkey hens and the relation of sperm numbers in the perivitelline layer of eggs Biology of Reproduction 43 271-275

Brillard JP, Galut O and Nys Y (1987) Possible causes of subfertility in hens following insemination near the time of oviposition British Journal of Poultry Science 28 307-318

Brillard JP, Beaumont C and Scheller MF (1998) Physiological responses of hens divergently selected on the number of chicks obtained from a single insemination Journal of Reproduction and Fertility 114 111-117

Burke WH and Ogasawara FX (1969) Presence of spermatozoa in uterovaginal fluids of the hen at various stages of the ovulatory cycle Poultry Science $\mathbf{4 8}$ 408-413

Burrows WH and Quinn JP (1937) The collection of spermatozoa from domestic fowl and turkey Poultry Science 16 19-24

Bushman AF, Van Krey HP, Denbow DM and Siegel PB (1985) Effect of the ovulatory cycle on oviductal sperm storage in the domestic fowl Theriogenology 23 473-479

Christensen VL (1981) Effect of insemination intervals on oviducal sperm storage in turkeys Poultry Science 60 2150-2156

Compton MM, Van Krey HP and Siegel PB (1978) The filling and emptying 
of the uterovaginal sperm-host glands in the domestic hen Poultry Science 57 1696-1700

Davis AP, Graham JK and Foote RH (1987) Homospermic versus heterospermic insemination of zona-free hamster eggs to assess fertility of fluorochrome-labeled acrosome-reacted bull spermatozoa Gamete Research 17 343-354

Durand RE and Olive PL (1982) Cytotoxicity, mutagenicity and DNA damage by Hoechst 33342 Journal of Histochemistry and Cytochemistry $30111-116$

Goodrich-Smith MA and Marquez BJ (1978) Estimation of the numbers of sperm storage tubules located at the uterovaginal junction in turkey oviduct Poultry Science $\mathbf{5 7} 1139$

Honig MG and Hume RI (1989) Dil and DiO: versatile fluorescent dyes for neuronal labeling and pathway tracing Trends in Neuroscience $\mathbf{1 2}$ 333-341

Johnson LA, Flook JP and Look MV (1987) Flow cytometry of X and $Y$ chromosome-bearing sperm for DNA using an improved preparation method and staining with Hoechst 33342 Gamete Research 17 203-212

Lake PE and Ravie O (1982) Effect on fertility of storing turkey semen for 24 hours at $10^{\circ} \mathrm{C}$ in fluids of different $\mathrm{pH}$ British Journal of Poultry Science $2341-47$

Lake PE and Wishart G (1984) Comparative physiology of turkey and chicken semen. In Reproductive Biology of Poultry pp 151-160 Eds F Cunningham, P Lake and D Hewitt. Longman Group, Harlow

Latt SA and Stetten G (1976) Spectral studies on 33258 Hoechst and related bisbenzimidazole dyes useful for fluorescent detection of deoxyribonucleic acid synthesis Journal of Histochemistry and Cytochemistry $\mathbf{2 4}$ 24-33

Ledley FD, Soriano HE, O'Malley BW, Jr, Lewis D, Darlington GJ and Finegold M (1992) Dil as a marker for cellular transplantation into solid organs Biotechniques 13 580-587

Lessells CM and Birkhead TR (1990) Mechanisms of sperm competition in birds: mathematical models Behavioral Ecology and Sociobiology 27 325-337

McDaniel CD, Bramwell RK and Howarth B, Jr (1997) Development of a novel fluorescence technique for quantifying the total number of spermatozoa stored in the uterovaginal junction of hens Journal of Reproduction and Fertility 109 173-179

McIntyre D, Quarles C, Fagerberg D and Krueger K (1982) Fertility of the turkey hen as affected by initial insemination and onset of egg production Poultry Science 61 1734-1737

McLean DJ and Froman DP (1996) Identification of a sperm cell attribute responsible for subfertility of roosters homozygous for the rose comb allele Biology of Reproduction 54 168-172

Mellish KS and Baker RD (1970) Marking boar spermatozoa with fluorochromes for evaluating spermatozoan transport within gilts Journal of Animal Science 31 917-922
Miller DJ, Demers JM, Braundmeier AG and Behrens ML (1998) The use of two fluorescent dyes to identify sperm in a competitive binding assay to oocytes Journal of Andrology 19 650-656

Overstreet JW and Adams CE (1971) Mechanisms of selective fertilization in the rabbit: sperm transport and viability Journal of Reproduction and Fertility 26 219-231

Parks JE and Lynch DV (1992) Lipid composition and thermotropic phase behavior of boar, bull, stallion and rooster sperm membranes Cryobiology $29255-266$

Parrish JJ and Foote RH (1985) Fertility differences among male rabbits determined by heterospermic insemination of fluorochrome-labeled spermatozoa Biology of Reproduction 33 940-949

Romanoff AL and Romanoff AJ (1963) Structure. In The Avian Egg pp 113-175. J Wiley and Sons, New York

Sexton T (1974) Oxidative and glycolytic activity of chicken and turkey spermatozoa Comparative Biochemistry and Physiology 48B 59-65

Staines HJ, Middleton RC, Laughlin KF and Wishart GJ (1998) Quantification of a sperm-egg interaction for estimating the mating efficiency of broiler breeder flocks British Poultry Science 39 273-277

Thomas PGA and Ball BA (1996) Cytofluorescent assay to quantify adhesion of equine spermatozoa to oviduct epithelial cells in vitro. Molecular Reproduction and Development 43 55-61

Van Krey HP, Ogasawara FX and Lorenz FW (1966) Distribution of spermatozoa in the oviduct and fertility in domestic birds. IV. Fertility of spermatozoa from infundibular and uterovaginal glands Journal of Reproduction and Fertility 11 257-262

Van Krey HP, Balander RJ and Compton MM (1981) Storage and evacuation of spermatozoa from the uterovaginal sperm-host glands in the domestic fowl Poultry Science 60 871-878

Vercelli A, Repici M, Garbossa D and Grimaldi A (2000) Recent techniques for tracing pathways in the central nervous system of developing and adult mammals Brain Research Bulletin 51 11-28

Wishart GJ (1987) Regulation of the length of the fertile period in the domestic fowl by numbers of oviducal spermatozoa, as reflected by those trapped in laid eggs Journal of Reproduction and Fertility $\mathbf{8 0}$ 493-498

Youakim A, Hathaway HJ, Miller DJ, Gong X and Shur BD (1994) Overexpressing sperm surface beta 1,4-galactosyltransferase in transgenic mice affects multiple aspects of sperm-egg interactions Journal of Cell Biology 126 1573-1583

Received 24 October 2000.

First decision 24 November 2000.

Final manuscript received 10 September 2001.

Accepted 10 September 2001. 